Our paper was not meant to be judgemental but was an attempt to make professionals aware of a group of people, however small, who have real problems relating to their culture, beliefs and language.

A. JAWAd SheIKH and SAEed FAROOQ, Mental Health Services, Bruce Burns Centre, Solihull Hospital, West Midlands B91 2JL

\section{Risk of violence to junior doctors}

Sir: Even if the commendable recommendations on the physical layout of assessment areas made in Lillywhite's article (Psychiatric Bulletin, January 1994, 19, 24-27) were met, I believe that junior doctors would still be at high risk of being the target of violent patients. The initiative of the College to familiarise junior doctors with 'breakaway' techniques will certainly improve the chances of doctors to reduce injury to themselves and patients, although if these skills are to be effective, they should be practised and revised at shorter and more frequent intervals than currently.

A useful addition to helping reduce the risk is to consider ways to prevent aggression before it begins. I propound training to improve skills in two areas: detection of cues of impending physical aggression of patients during interviews and learning methods to defuse verbal aggression of patients, so often present and at times the prelude to physical violence. I suggest the use of expert tuition using video and role-play techniques.

DAVID MARCHEVSKY, Bentham Unit, Ealing Hospital, Southall, Middlesex UB1 3EU

Supervision registers: is there the need for a referendum among poychiatrists?

Sir: I wish to join the growing number of psychiatrists who say that 'strong concern' about the guidance on the introduction of supervision registers is not enough. I am in complete agreement with Dr David Gill (Psychiatric Bulletin, 1994, 18, 773-774) that we must not collude with something which not only "threatens ctvil liberties and breaches confidentiality" but also increases stigma and implicitly endorses a simplistic direct link between violence and mental illness, which is incorrect.
Like him, I have been amazed at the number of psychiatrists who appear to conform because the government says they should. However, I remain optimistic that many of my colleagues are individually resisting and I would like to suggest a referendum or similar measure. If the majority of Members and Fellows of the College voted to refuse to implement the register, the NHS Executive would have no choice but to withdraw the present guidelines.

At the risk of stating the obvious, it is vital that psychiatrists clearly emphasise that the most, indeed the only, effective mental health services are ones which are well-resourced and userfriendly and which engage the large majority of seriously mentally ill patients in voluntary participation and treatment. An efficient care programme approach can and should incorporate all that is necessary to identify, target, actively assess and review, with assertive outreach and multi-agency and multi-district communication when appropriate, the same particularly vulnerable group outlined in the supervision register guidelines. Therapeutically the register is both superfluous and counter-productive.

The government is now pursuing new legislation in the form of a supervised discharge order. Should this controversial proposal become law, there would, of course, be a logical basis for a supervision register within a clear legal framework.

Auson Abraham, Mid Sussex NHS Trust, The Princess Royal Hospital, Haywards Heath, West Sussex RH16 4EX

\section{NHS superannuation regulations}

Sir: May I draw attention to some errors in Dr M. J. Harris's note on the NHS superannuation regulations (Psychiatric Bulletion. $1994,18,713$ ).

Under the regulations a mental health officer is a whole-time member of the staff of a hospital used for the treatment of persons suffering from mental disorders who is employed for the whole, or almost the whole. of his time in the treatment or care of such persons or a maximum part-time specialist employed solely in the treatment of the mentally disordered.

It should be noted that, to qualify for mental health officer status, whole-time employees must be employed "for the whole, or almost 